\title{
Surface characterization of silver and palladium modified glassy carbon
}

\author{
ALEKSANDRA A PERIĆ-GRUJIĆ*, OLIVERA M NEŠKOVIĆ ${ }^{\dagger}$, MIOMIR V VELJKOVIĆ ${ }^{\dagger}$, \\ ZORAN V LAUŠEVIĆ ${ }^{\dagger}$ and MILA D LAUŠEVIĆ \\ Faculty of Technology and Metallurgy, University of Belgrade, Karnegijeva 4, Belgrade, Serbia \\ †'Institute of Nuclear Sciences 'Vinča', Belgrade, Serbia
}

MS received 14 February 2007; revised 18 September 2007

\begin{abstract}
In this work, the influence of silver and palladium on the surface of undoped, boron doped and phosphorus doped glassy carbon has been studied. The silver and palladium concentrations in solution, after metal deposition, were measured by atomic absorption spectrophotometer. The morphology of metal coatings was characterized by scanning electron microscopy. In order to investigate the nature and thermal stability of surface oxygen groups, temperature-programmed desorption method combined with mass spectrometric analyses, was performed. The results obtained have shown that silver and palladium spontaneously deposit from their salt solutions at the surface of glassy carbon samples. Silver deposits have dendrite structure, whilst palladium forms separate clusters. The highest amount of both silver and palladium deposits at the surface of sample containing the highest quantity of surface oxide complexes. It has been concluded that carboxyl groups and structure defects are responsible for metal reduction. Calculated desorption energies have shown that the surface modification by metal deposition leads to the formation of more stable surface of undoped and doped glassy carbon samples.
\end{abstract}

Keywords. Glass-like carbon; doping; surface modification; mass spectroscopy; temperature programmed desorption; surface properties.

\section{Introduction}

The possibility of preparing carbon materials with controlled surface properties is very important due to the wide range of carbon materials application. There are two major approaches to influence the surface of carbon materials. The first approach is the incorporation of heteroatoms, which affects the surface activity and oxidation resistance. A number of studies have been focused on the surface modification of carbon materials by introducing boron or phosphorus heteroatoms. Substitutional boron has shown both catalytic and inhibiting effect on carbon oxidation. The dominant factor depends on boron content and distribution, carbon nature and reaction conditions (McKee et al 1984; Zhong et al 2000; Lee et al 2004). The oxidation inhibition mechanism in phosphorus doped carbon fabrics appears to block active sites resulting in the proportional increase of oxidation inhibition with increasing phosphorus loading (Lee and Radovic 2003).

The modification of glassy carbon through the introduction of boron and phosphorus heteroatoms in the carbon precursor has been reported (Laušević et al 1990;

*Author for correspondence (alexp@tmf.bg.ac.yu)
Perić et al 1996a, b; Đurkić et al 1997; Perić-Grujić et al 2006). Characterization of the surface properties using $X$ ray photoelectron spectroscopy (XPS) has shown that phenol, alcohol, ether, carbonyl, semiquinone, carboxyl, acid anhydride and lactone functional groups exist on glassy carbon surface (Sundberg et al 1989; Đurkić et al 1997). Previous mass-analysed temperature programmed desorption (TPD) experiments have shown that the main desorption products, $\mathrm{CO}$ and $\mathrm{CO}_{2}$, result from the decomposition of different surface oxygen complexes (Roman-Martinez et al 1993; Zhuang et al 1994; Đurkić et al 1997).

The other approach to influence the surface of carbon materials is to prepare superficially modified materials by spreading coatings with deposits or thin films. Previous studies have shown that some metals, like silver, copper and palladium, can be deposited spontaneously at the surface of carbon materials from their salt solutions (Dentzer et al 1986; Ehrburger et al 1987; Dekanski et al 1990). Glassy carbon modified by silver deposition has electrocatalytic properties. Such prepared material can be used as an indicator electrode in potentiometric titrations (Dekanski et al 2001), as well as in commercial applications with regard to the separation of precious metals from ores (Konova et al 2005).

Since previous results refer to either doped or surface modified glassy carbon, in this work, the influence of 
silver and palladium surface modification on the surface properties of doped glassy carbon has been studied. In order to compare doped and undoped samples, undoped surface modified samples were examined, as well. Massanalysed TPD experiments were performed in order to investigate the nature and thermal stability of surface oxygen groups. The apparatus consisting of temperatureprogrammed furnace and quadrupole mass spectrometer (MS) has been constructed in our laboratory (Perić et al 1996a, b; Perić-Grujić et al 1998).

\section{Experimental}

\subsection{Sample preparation}

Glassy carbon was produced by the carbonization of a commercial phenol-formaldehyde resin. Three types of precursor resin samples were prepared: (i) phenol-formaldehyde resin without any additions in order to obtain pure glassy carbon precursor before polymerization, (ii) phenolformaldehyde resin mixed with boric acid, to obtain $2 \mathrm{wt} \%$ of boron in glassy carbon precursor before polymerization and (iii) phenol-formaldehyde resin mixed with phosphorus pentoxide, to obtain $2 \mathrm{wt} \%$ of phosphorus in glassy carbon precursor before polymerization. Polymerization of resin was carried out at $363 \mathrm{~K}$ for $24 \mathrm{~h}$. The polymer was carbonized in argon up to $1273 \mathrm{~K}$ with a heating rate of $12 \mathrm{Kh}^{-1}$. Prepared undoped, boron doped and phosphorus doped glassy carbon samples were further treated: (i) all three samples were immersed in $\mathrm{AgNO}_{3}$ solution $\left(50 \mathrm{mg} \mathrm{dm}^{-3}\right)$ for 7 days and (ii) all three samples were immersed in $\mathrm{PdCl}_{2}$ solution $\left(50 \mathrm{mg} \mathrm{dm}^{-3}\right)$ for 7 days. Samples were then removed from salt solutions and rinsed in water until a negative reaction to $\mathrm{Ag}^{+}$or $\mathrm{Pd}^{2+}$ ions was achieved. After metal deposition, the concentration of silver and palladium in solution was measured by atomic absorption spectrophotometer, PYU UNICAM SP9, Philips. The morphology of silver and palladium deposits at the glassy carbon surface was characterized by scanning electron microscopy (SEM JEOL-T20). Further, TPDMS analyses were performed. In each TPD-MS experiment, $50 \mathrm{mg}$ of powdered sample was used.

\section{$2.2 T P D-M S$}

The $20 \mathrm{~cm}^{3}$ desorption chamber, constructed from stainless steel, was pumped down to the $10^{-7}$ mbar range. The desorption chamber was placed in a temperature-programmed furnace connected to the gas-inlet system of an EAI QUAD 210 quadrupole mass spectrometer (Electronic Associates, Inc., CA, USA) via a stainless steel tube $(50 \mathrm{~cm}$ long). A platinum/platinum-rhodium thermocouple was used for temperature measurements. To perform a TPD scan, after pumping for $30 \mathrm{~min}$ at room temperature, samples were heated by linearly increasing the temperature
( $2 \mathrm{~K} / \mathrm{min}$ ). A Transitrol 12-90B temperature controller was used to program the temperature between $373 \mathrm{~K}$ and 1273 K. Data acquisition during heating time was achieved using the channeltron detector, a Gould digital storage oscilloscope (Model 4050) and an IBM PC computer with GPIB/IEE 488 interface so that the ion signals at $\mathrm{m} / \mathrm{z} 28$ and $44\left(\mathrm{CO}\right.$ and $\left.\mathrm{CO}_{2}\right)$ were simultaneously recorded as a function of temperature. The laminar flow was achieved from the furnace to the mass spectrometer. The intensity of the $\mathrm{m} / \mathrm{z} 28$ signal was corrected for the contribution of background $\mathrm{N}_{2}$ signal intensity.

\subsection{Quantitative analysis}

In order to compare all the results quantitatively, the amount of desorbed $\mathrm{CO}$ and $\mathrm{CO}_{2}$ for each sample was calculated. The calibration method included the use of suitable salts, i.e. $\mathrm{CaC}_{2} \mathrm{O}_{4}$ for $\mathrm{CO}$ calibration and $\mathrm{CaCO}_{3}$ for $\mathrm{CO}_{2}$ calibration (Perić-Grujić 1998). The results were obtained in $\mu \mathrm{molg}^{-1} \mathrm{~K}^{-1}$ of each desorbed gas.

\section{Results and discussion}

In this work, the influence of surface modification on the surface properties of undoped and doped glassy carbon has been studied. In figure 1 , the amounts of silver and palladium metal deposits on undoped (GC), boron doped (GCB) and phosphorus doped (GCP) glassy carbon samples are presented.

It can be noticed that the highest amount of metals has been deposited at the surface of GCP sample, while the lowest has been observed at the surface of GC sample. The amounts of deposited silver are always higher than the corresponding amounts of deposited palladium.

The morphology of silver and palladium deposits at the glassy carbon surface was characterized by scanning elec-

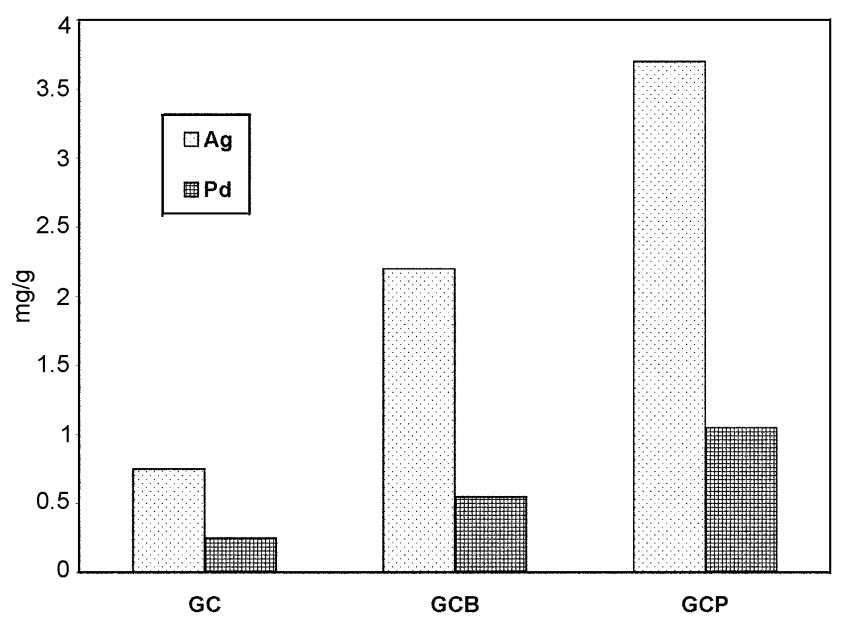

Figure 1. The amounts of deposited silver and palladium on GC, GCB and GCP samples. 

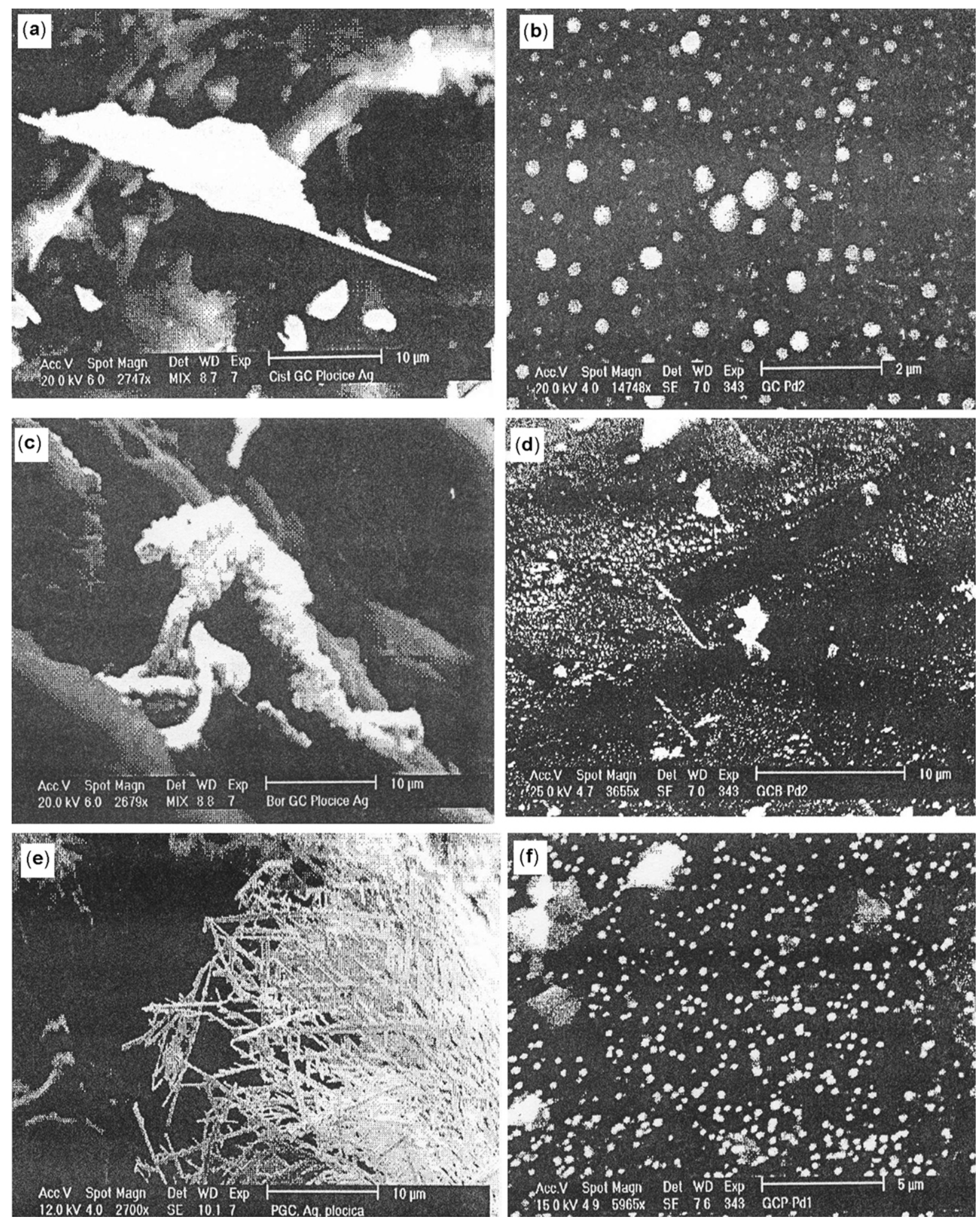

Figure 2. Morphology of metal deposits: (a) GC-Ag, (b) GC-Pd, (c) GCB-Ag, (d) GCB-Pd, (e) GCP-Ag and (f) GCP-Pd.

tron microscopy (SEM). The SEM results (figure 2) have shown that silver on glassy carbon has dendrite structure, whilst palladium forms separate clusters.

In order to follow the influence of surface modification on the surface properties of undoped and doped samples, the TPD-MS spectra of silver or palladium surface modified GC, GCB and GCP samples were recorded. The most significant products of TPD obtained were $\mathrm{CO}(\mathrm{m} / \mathrm{z} 28)$ and $\mathrm{CO}_{2}(\mathrm{~m} / \mathrm{z} 44)$. The amounts of desorbed $\mathrm{CO}$ and $\mathrm{CO}_{2}$ from unit mass of each sample were calculated and pre- 
sented as a function of desorption temperature. Corresponding values for GC, GCB and GCP samples which were not superficially modified, obtained in our previous work (Đurkić et al 1997; Perić-Grujić 1998), were added in the diagrams, as dotted lines.

\subsection{GC samples}

The amounts of desorbed $\mathrm{CO}$ (a) and $\mathrm{CO}_{2}$ (b) as a function of desorption temperature, for undoped, glassy carbon (GC) samples, before and after surface modification, are presented in figure 3 .

Two CO desorption maxima ( $573 \mathrm{~K}$ and $1073 \mathrm{~K}$ ) in the case of GC sample before surface modification indicate the presence of less stable carbonyl and/or ether and more stable semiquinone groups, respectively (Roman-Martinez et al 1993; Zhuang et al 1994). After surface modification, the same types of oxide groups are present, but corresponding $\mathrm{CO}$ desorption maxima are shifted towards higher temperatures indicating higher thermal stability of these groups. Higher amount of semiquinone groups after surface modification is evident. Two $\mathrm{CO}_{2}$ desorption maxima ( $723 \mathrm{~K}$ and $923 \mathrm{~K}$ ) correspond to the decomposition of less stable carboxyl and more stable acid anhydride and/or lactone species, respectively (Zhuang et al 1994). After surface modification, corresponding $\mathrm{CO}_{2}$
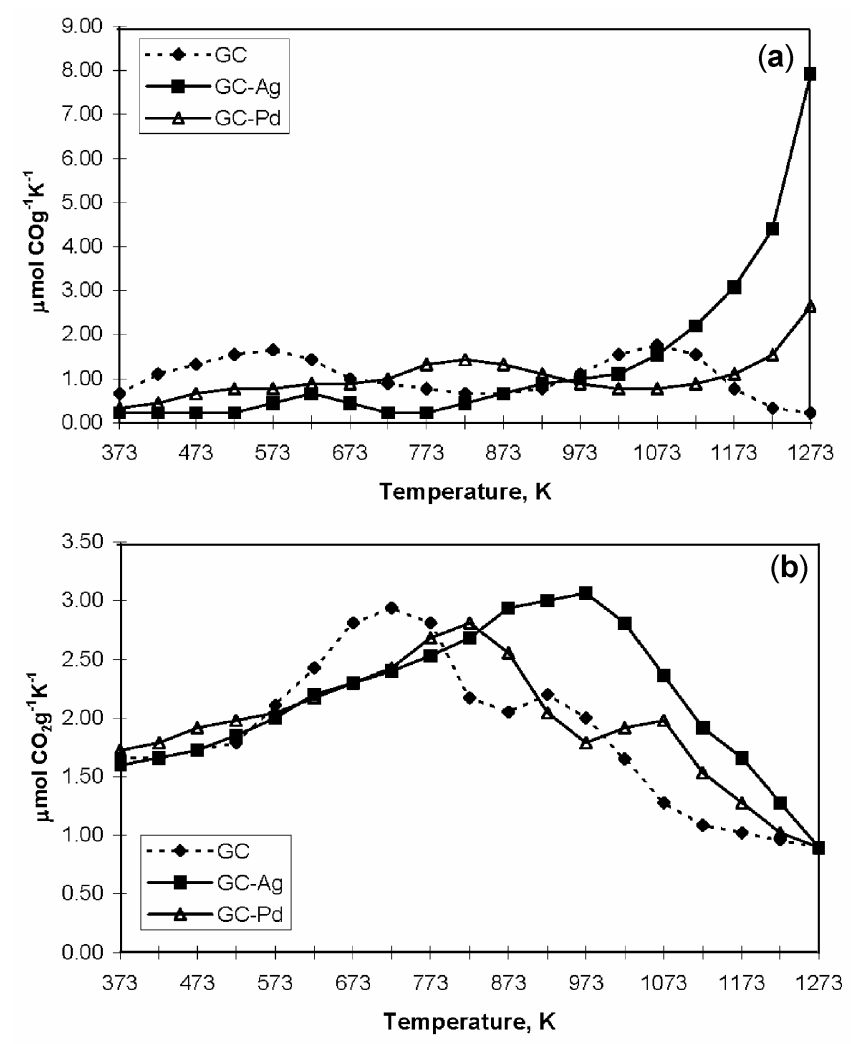

Figure 3. The amounts of desorbed (a) $\mathrm{CO}$ and (b) $\mathrm{CO}_{2}$ as a function of desorption temperature, for $\mathrm{GC}$ samples, before and after surface modification. desorption maxima are shifted towards higher temperatures. In the case of silver modified sample, it can be noticed that there is no temperature maximum around $700 \mathrm{~K}$, thus indicating the absence of carboxyl groups. Both silver and palladium modified samples contain higher amounts of acid anhydride and/or lactone groups, than the GC sample before modification.

From the results presented, it can be assumed that surface modification of pure glassy carbon leads to the formation of more stable surface with higher amount of semiquinone, acid anhydride and/or lactone groups. The highest amount of these thermally stable species has been established at the surface of silver modified GC sample. Moreover, the absence of carboxyl groups on silver modified sample indicates that silver deposition leads to the conversion of these groups into more stable surface species and thus, enhanced bonding energy of the surface oxide complexes. The differences between silver and palladium modified samples can be explained by the differences in morphology of metal deposits.

\subsection{GCB samples}

In figure 4, the amounts of desorbed $\mathrm{CO}$ (a) and $\mathrm{CO}_{2}$ (b) as a function of desorption temperature, for GCB samples, before and after surface modification are presented.
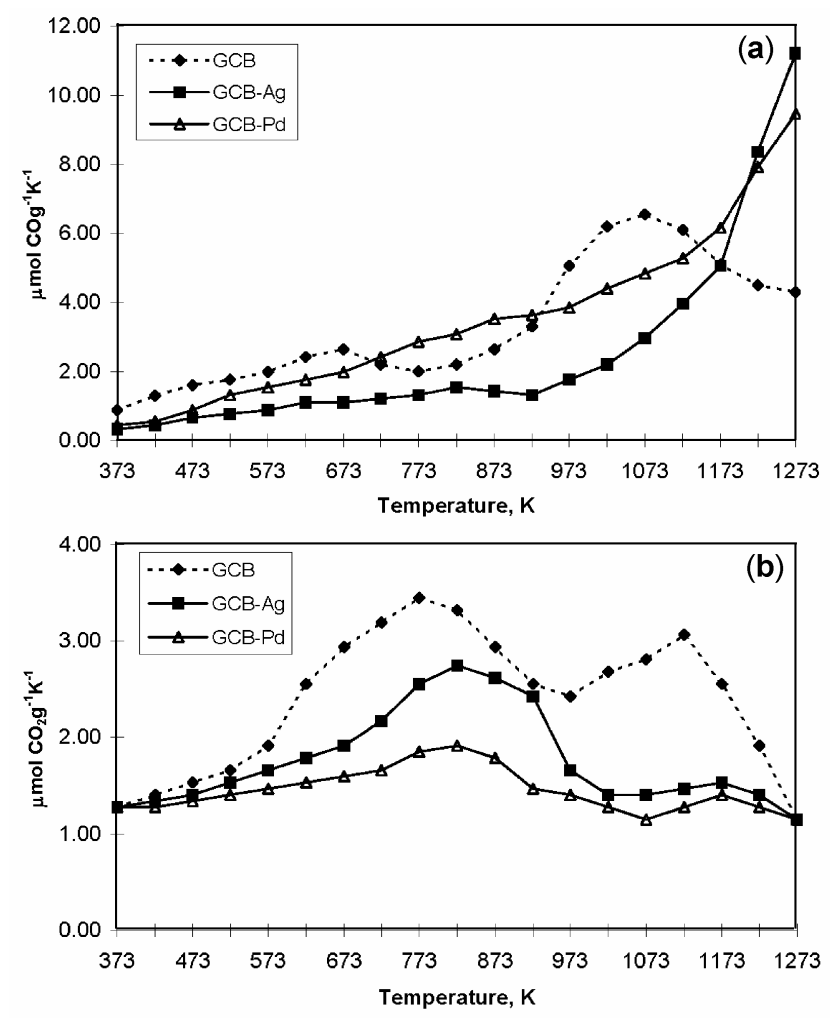

Figure 4. The amounts of desorbed (a) $\mathrm{CO}$ and (b) $\mathrm{CO}_{2}$ as a function of desorption temperature, for GCB samples, before and after surface modification. 
Before surface modification, at the surface of GCB sample, the presence of carbonyl and/or ether and semiquinone groups result in $\mathrm{CO}$ desorption (figure 4a). After surface modification, higher amounts of more stable semiquinone groups have been observed. Carboxyl, acid anhydride and/or lactone groups (figure $4 b$ ), which decompose resulting in $\mathrm{CO}_{2}$ desorption, are present at the surfaces of GCB samples, before and after surface modification. Nevertheless, the amount of these groups is lower and their stability is higher after surface modification.

Our previous results (Đurkić et al 1997) have shown that boron, which incorporates into the carbon lattice substitutionally, typically enhances the amount of surface oxide groups. After surface modification, the amount of all oxide species has been typically reduced, except the amount of very stable semiquinone groups. The higher amounts of semiquinone groups could be a consequence of conversion of some less stable groups into more stable semiquinone species during metal reduction. This indicates that groups with lower stability are responsible for silver and palladium reduction and their deposition in metallic form (Baćić-Vukčević et al 2006). On the other hand, deposits of silver and palladium at the surface of GCB sample could block reactive carbon sites, thus resulting in reduced number of oxide groups.

\subsection{GCP samples}

The amounts of desorbed $\mathrm{CO}$ (a) and $\mathrm{CO}_{2}$ (b) as a function of desorption temperature, for GCP samples, before and after surface modification are presented in figure 5 .

Three CO desorption maxima (figure 5a) at the surface of GCP sample before surface modification indicate the presence of carbonyl and/or ether, acid-anhydride and semiquinone groups, respectively (Roman-Martinez et al 1993; Zhuang et al 1994). After surface modification, the presence of very stable semiquinone groups is evident. The amount of all groups is lower after surface modification. $\mathrm{CO}_{2}$ desorption maxima (figure $5 \mathrm{~b}$ ) indicate the presence of acid-anhydride species, before and after surface modification. The amount of these groups is lower and their stability is higher after surface modification. The presence of carboxyl groups has been observed neither before nor after surface modification.

Our previous results (Đurkić et al 1997) have shown that the presence of phosphorus in glassy carbon contributes to the typically increased amount of surface oxide groups. An increased quantity of chemisorbed oxygen complexes on GCP surface has been related to the increased disorder of glassy carbon structure caused by the presence of a second phosphorus phase observed by Xray diffraction (Đurkić et al 1997). Calculated amounts of deposited metals have shown that the highest amount of silver and palladium has been deposited at the surface of GCP sample which, actually, contains the highest total amount of surface oxide groups, compared with GC and GCB samples. After surface modification of GCP sample, the amount of all oxide species has been reduced, while the presence of carboxyl groups has been observed neither before nor after surface modification. It has been noticed that when carboxyl groups are present (GC and GCB samples), the amounts of acid-anhydride and semiquinone groups, on GC sample, and semiquinone groups on GCB sample, increase after surface modification, indicating that carboxyl groups convert into more stable species. In agreement with previous studies (Baćić-Vukčević et al 2006), it can be concluded that carboxyl groups are responsible for metal reduction. On the other hand, assuming that the presence of a second phosphorus phase increases disorder of glassy carbon structure, structure defects could be responsible for silver and palladium reduction. Lower quantity of all oxide groups on GCP sample after surface modification could be a consequence of blockage of reactive sites, due to the high amount of metal deposits.

\subsection{Relation between amounts of surface oxide groups and metal deposits}

On the basis of TPD-MS graphs, the amounts of CO- and $\mathrm{CO}_{2}$-evolving groups, before surface modification, were
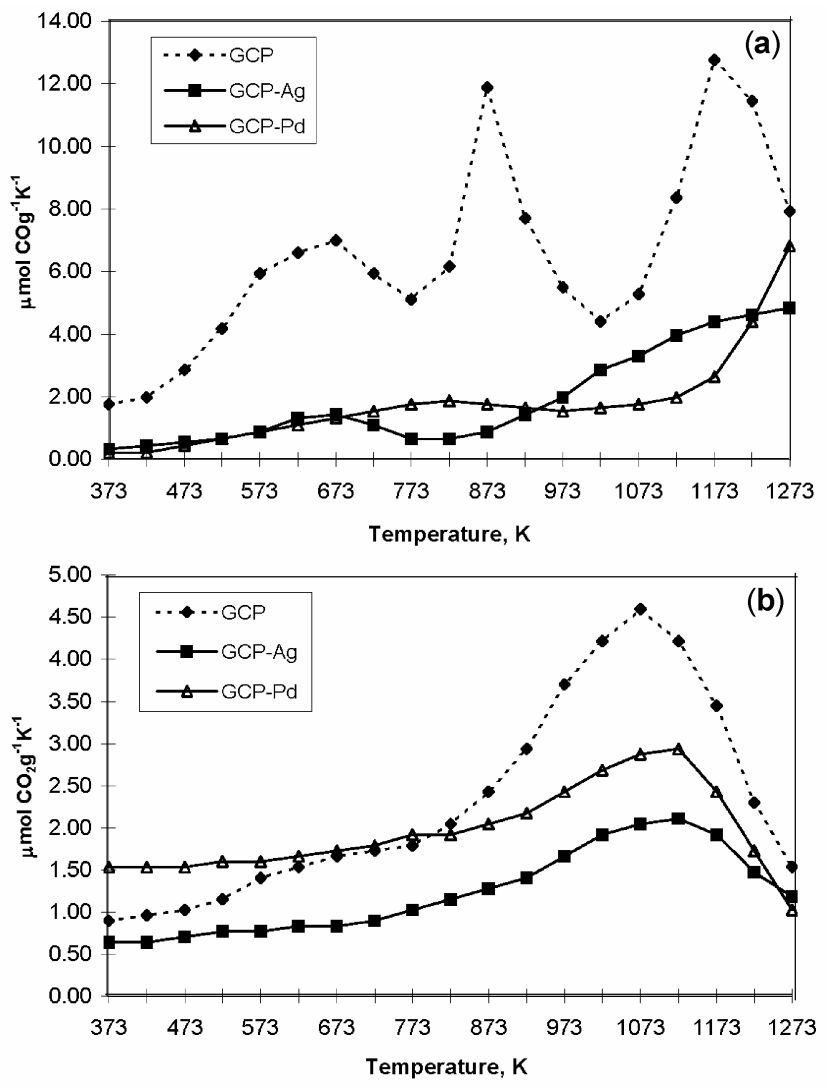

Figure 5. The amounts of desorbed (a) $\mathrm{CO}$ and (b) $\mathrm{CO}_{2}$ as a function of desorption temperature, for GCP samples, before and after surface modification. 
Table 1. Total amounts of $\mathrm{CO}$ - and $\mathrm{CO}_{2}$-evolving groups before surface modification and amounts of metal deposits.

\begin{tabular}{lcccc}
\hline Sample & $\begin{array}{c}\text { CO-evolving } \\
\text { group }\left(\mathrm{mmolg}^{-1}\right)\end{array}$ & $\begin{array}{c}\mathrm{CO}_{2} \text {-evolving } \\
\text { group }\left(\mathrm{mmolg}^{-1}\right)\end{array}$ & $\mathrm{Ag}\left(\mu \mathrm{molg}^{-1}\right)$ & $\mathrm{Pd}\left(\mu \mathrm{molg}^{-1}\right)$ \\
\hline GC & 0.90 & 1.98 & 6.95 & 2.35 \\
GCB & 3.96 & $2 \cdot 07$ & 20.39 & 5.17 \\
GCP & 13.50 & $2 \cdot 52$ & 34.29 & 9.87 \\
\hline
\end{tabular}

Table 2. Desorption products and corresponding desorption energies for GC, GCB and GCP samples before and after surface modification.

\begin{tabular}{lccc}
\hline $\begin{array}{l}\text { Desorption } \\
\text { product }\end{array}$ & Sample & \multicolumn{2}{c}{ Desorption energy $\left(\mathrm{kJmol}^{-1}\right)$} \\
\hline $\mathrm{CO}$ & GC & 151 & 238 \\
& GC-Ag & 164 & $>336$ \\
& GC-Pd & 217 & $>336$ \\
& GCB & 178 & $>336$ \\
& GCB-Ag & $/$ & $>336$ \\
& GCB-Pd & $/$ & $>336$ \\
& GCP & 178 & 310 \\
& GCP-Ag & 178 & $>336$ \\
& GCP-Pd & 217 & $>336$ \\
$\mathrm{CO}_{2}$ & GC & 191 & 244 \\
& GC-Ag & $/$ & 257 \\
& GC-Pd & 217 & 283 \\
& GCB & 204 & 296 \\
& GCB-Ag & 217 & 310 \\
& GCB-Pd & 217 & 310 \\
& GCP & $/$ & 283 \\
& GCP-Ag & $/$ & 296 \\
& GCP-Pd & $/$ & \\
\hline
\end{tabular}

calculated. In table 1 , the amounts of $\mathrm{CO}$ - and $\mathrm{CO}_{2}$ evolving groups and amounts of metal deposits on corresponding samples are presented.

It can be noticed that higher amounts of metals are deposited on sample surfaces with higher content of surface oxide groups. On the other hand, the enhancement of amounts of metal deposits is not proportional to the enhancement of surface oxide group content. This indicates that not only surface oxide complexes are responsible for metal reduction and deposition, but also structure defects, as possible electron donors, could be responsible for silver and palladium reduction.

\subsection{Stability of surface oxide complexes}

Assuming that the desorption energy reflects the stability of the chemisorption bond, in order to compare and discuss the stability of samples before and after surface modification, desorption energy, $E_{\mathrm{d}}$, has been calculated using the peak-position method (Tompkins 1978; Zhou et al 1994):

$$
E_{\mathrm{d}}=R T_{\mathrm{m}} \ln (v / \beta),
$$

where $R$ is a gas constant, $T_{\mathrm{m}}$ the peak temperature, i.e. the temperature at which the desorption rate has maximal value, $\beta$ the linear heating rate $(\beta=2 \mathrm{~K} / \mathrm{min})$ and $v$ a frequency factor of the chemisorption bond $\left(v=10^{13} \mathrm{~s}^{-1}\right)$. The desorption energies calculated from the position of peak maxima are listed in table 2 .

All calculated desorption energies are higher than $100 \mathrm{~kJ} \mathrm{~mol}^{-1}$, indicating that the chemisorption processes are involved. Desorption energies of corresponding oxide groups are typically higher after surface modification, indicating their higher stability compared with not superficially modified samples. If the difference between the influence of silver and palladium deposition is considered, it can be noticed that palladium deposition leads to the formation of more stable carbonyl and/or ether groups on GC and GCP samples and acid-anhydride groups on GC sample. The other corresponding desorption energy values for silver and palladium modified samples are the same, indicating similar effect of silver and palladium deposition to the surface stability. From the results obtained, it can be concluded that metal deposition leads to the formation of more stable surface of undoped and doped samples.

\section{Conclusions}

Silver and palladium spontaneously deposit from their salt solutions at the surface of undoped, boron doped and phosphorus doped glassy carbon. The highest amount of both silver and palladium has been deposited at the surface of GCP sample which contains the highest quantity of surface oxide complexes. The lowest amount of metal has been deposited on GC sample which contains the lowest quantity of surface oxide complexes. The amounts of deposited silver are always higher than corresponding amounts of deposited palladium.

The SEM results have shown that silver on glassy carbon has dendrite structure, whilst palladium forms separate clusters.

TPD-MS analyses have shown that surface modification of GC and GCB samples leads to the conversion of less stable carboxyl into more stable species. After surface modification of GCP sample, the surface with lower content of all oxide groups has been obtained. On the basis of 
results obtained, it has been concluded that carboxyl groups as well as structure defects, are responsible for metal reduction.

Calculated desorption energies have shown that after surface modification more stable surfaces of undoped, boron doped and phosphorus doped samples have been obtained.

\section{Acknowledgements}

The authors are grateful to the Ministry of Science and Environment Protection of the Republic of Serbia for financial support.

\section{References}

Baćić-Vukčević M et al 2006 Mater. Sci. Forum 518217

Dekanski A et al 1990 Vacuum 411772

Dekanski A et al 2001 Carbon 391207
Dentzer J et al 1986 J. Colloid Interface Sci. 112170

Đurkić T et al 1997 Carbon 351567

Ehrburger P et al 1987 Carbon 25129

Konova O N et al 2005 Carbon 4317

Lauševic M et al 1990 Rapid Commun. Mass Spectrom. 4515

Lee Y J and Radovic L R 2003 Carbon 411987

Lee Y J et al 2004 Carbon 422233

McKee D W et al 1984 Carbon 22 285, 507

Perić-Grujić A 1998 Mass spectrometric analysis of glass-like carbon surface chemistry by temperature programmed desorption, $\mathrm{Ph} \mathrm{D}$ Thesis, University of Belgrade, Belgrade

Perić A et al 1996a J. Serb. Chem. Soc. 61803

Perić A et al 1996b Rapid Commun. Mass Spectrom. 101233

Perić-Grujić A et al 1998 Hem. Ind. 52520

Perić-Grujić A et al 2006 Bull. Mater. Sci. 29467

Roman-Martinez M C et al 1993 Carbon 31895

Sundberg K M et al 1989 J. Electrochem. Soc. 136434

Tompkins F C 1978 Chemisorption of gases on metals (London: Academic Press) p. 77

Zhong D H et al 2000 Carbon 381199

Zhou S et al 1994 J. Therm. Anal. 41767

Zhuang Q L et al 1994 Carbon 32539 